УДК 634.0.813

\title{
СТРУКТУРНЫЕ ИЗМЕНЕНИЯ В ДРЕВЕСИНЕ ДУБА ПОД ВЛИЯНИЕМ УЛЬТРАЗВУКА
}

\author{
() Г.Ф. Антонова ${ }^{l^{*}}$, Ю.А. Ольхов ${ }^{2}$ Н.Т. Коновалов ${ }^{3}$ \\ ${ }^{1}$ Институт леса им. В.Н. Сукачева СО РАН, Академгородок, Красноярск, \\ 660036 (Россия), e-mail: institute_forest@ksc.krasn.ru \\ ${ }^{2}$ Институт проблем химической фризики РАН, пр. академика Семенова, 1, \\ Черноголовка, 142432 (Россия) \\ ${ }^{3}$ Институт твердого тела РАН, ул. академика Осипьяна, 2, Черноголовка, \\ 142432 (Россия)
}

Изменения в структуре древесины дуба под влиянием ультразвука изучались методом термомеханической спектрометрии. Установлены различия молекулярно-релаксационных характеристик древесины в аксиальном и радиальном направлениях относительно роста дерева до и после воздействия ультразвука. Реакция структурных блоков на действие ультразвука обусловлена пространственным расположением морфологических элементов древесины и их размерами относительно оси дерева и надмолекулярным строением составляющих их полимеров.

Ключевые слова: древесина дуба, ультразвук, термомеханическая спектроскопия.

\section{Введение}

Древесина растений является природным полимером нерегулярного строения. Особенно сложным морфологическим строением обладает древесина лиственных пород. Древесина дуба, который принадлежит к кольцесосудистым видам, содержит раннюю и позднюю ксилему. Характерными структурными элементами древесины являются: крупные сосуды ранней, мелкие сосуды поздней, трахеиды, волокона либриформа, присутствующие в основном в позднем слое и придающие древесине прочность, а также паренхимные элементы в виде узких и широких сердцевинных лучей и митохондриальной паренхимы [1]. Существуют различия и в микроскопическом строении ранней и поздней древесины: тангентальном и радиальном размерах сосудов, рядности лучей.

На надмолекулярном уровне древесина, согласно общепринятой модели [2], представляет собой армированную полимерную композицию, в которой целлюлоза образует жестко сцепленную фибриллярную арматуру, а лигнин и гемицеллюлозы - аморфную матрицу. Материал матрицы заполняет пространство между фибриллами и может рассматриваться как суперпозиция трех взаимопроникающих полимерных сеток. Это сетка углеводов, образуемая за счет водородных связей и сил физического взаимодействия (Н-сетка), сетка между углеводами и лигнином, образуемая за счет химической (в случае древесины - ковалентной) связи (ЛУ-сетка), и сетки между макромолекулами лигнина, образуемые за счет физических сил (Л-сетка).

Изменения в древесине дуба и ее компонентах, возникающих под воздействием ультразвука (УЗ)

Антонова Галина Феодосиевна - доктор биологических наук, ведущий научный сотрудник, e-mail: institute_forest@ksc.krasn.ru, antonova_cell@mail.ru Ольхов Юрий Андреевич - кандидат химических наук, старший научный сотрудник, e-mail: olkhov@icp.ac.ru Коновалов Николай Тимофеевич - кандидат технических наук высокой и низкой мощности, исследовались ранее в основном морфометрией и химическими методами [3-6]. Знакопеременные напряжения, возникающие при ультразвуковой обработке такой сложной полимерной структуры, как древесина, вызывают в ней колебательные деформации стенок клеток и содержащихся в них высокомолекулярных соединений.

\footnotetext{
* Автор, с которым следует вести переписку.
} 
Интенсивное ультразвуковое воздействие на полимеры способно вызвать деструкцию макромолекулярных цепей, привести к возможному повороту сегментов цепей, т.е. к изменению их молекулярной конформации. Колебательные деформации при определенных амплитудах могут способствовать также раздвижению фибриллярных рядов и разрыву водородных и межмолекулярных связей смежных волокон.

В последнее время для анализа молекулярно-топологического строения полимеров и полимерных композиций стал применяться метод термомеханической спектроскопии, разработанный и теоретически обоснованный в Институте химической физики РАН, который позволяет, не разрушая структуру полимера, диагностировать его молекулярно-топологическое строение [7, 8]. Метод с успехом использовался для полимеров со структурой полувзаимо- и взаимопроникающих полимерных сеток, в том числе для характеристики древесины осины в естественном и модифицированном состоянии [9-13].

В основу метода положены два фундаментальных свойства макромолекул полимера, помещенного в переменное во времени температурное поле. Одно из них - сегментальная релаксация макромолекул и их переход в режим молекулярного течения, или золь-состояние. Согласно второму - в момент достижения гомологами температуры, при которой за счет деструкции физической сетки и снижения модулей упругости ( $\mathrm{E}_{\mathrm{i}}$ : вдоль волокон, в радиальном и тангенциальном направлениях) начинается молекулярное «течение», в нагруженном полимере происходит деформационный скачок, пропорциональный весовой доле этих гомологов. Возникающие деформационные скачки позволяют определять релаксационные параметры, фазовое состояние и молекулярные характеристики фрагментов макромолекул в структуре топологических блоков, проводить молекулярный анализ кристаллической фракции в аморфно-кристаллических полимерах.

Оценка воздействия УЗ на древесину дуба с помощью метода термомеханической спектрометрии (TMC) может дать дополнительную интересную информацию об изменениях в древесине как природном полимере под влиянием ультразвука.

Целью работы было исследование молекулярно-топологического строения древесины дуба до и после воздействия ультразвука с помощью метода ТМС.

\section{Материалы и методы}

Материалом для исследования молекулярно-топологического строения древесины дуба методом термомеханической спектрометрии служила древесина дуба черешчатого (Quercus robur L.), выдержанная на воздухе в течение 5,5 года до и после ультразвуковой обработки.

Для акустической обработки древесины использовали бруски размером $130 \times 40 \times 18$ мм. Максимальный размер ( $\mathrm{L}=130$ мм) совпадает с направлением роста дерева и составляет половину волны $(\lambda / 2)$, Образцы древесины (влажность 14-16\%) обрабатывали ультразвуком с частотой 21,5 кГц и интенсивностью излучения 15 Вт/см².

Установка для обработки образцов древесины ультразвуком включала: ультразвуковой генератор УЗГ-1-1, магнитострикционный преобразователь ПМС-1-1 и волноводно-стержневую систему с концентратором. Для обеспечения акустического контакта торец концентратора жестко соединялся с входным торцом образца, а выходной торец образца - с акустической развязкой опорного устройства. Акустическая развязка представляла собой заготовку из той же древесины длиной четверть волны ( $\lambda / 4)$. Акустическую обработку образцов осуществляли в прерывистом (импульсном) режиме, что предотвращает локальный разогрев образца в местах его контакта с волноводом и акустической развязкой. Величина активной фазы (длительность сигнала) составляла 10 с, фаза молчания (т.е. пауза для релаксации) - 20 с.

Комплексную диагностику молекулярно-топологического строения древесины дуба до и после акустической обработки проводили в двух вариантах. По одному из них использовали бруски с плоскопараллельными гранями, ориентированными вдоль, во втором - поперек оси роста дерева, т.е. при соосной (параллельной) $(\|)$ и взаимно-перпендикулярной $(\perp)$ ориентациях оси роста дерева, и приложения к образцу термомеханической нагрузки $\left(\mathrm{P}_{\mathrm{o}}=25\right.$ г).

Термомеханический анализ проводили методом погружения (пенетрации) в образец древесины кварцевого полусферического зонда радиусом $\mathrm{R}_{0}=2$ мм, динамика, взаимодействия которого с поверхностью полимера проанализирована в работах $[10,11]$. Затем образец помещали в термокамеру анализатора марки УИП-70м. Охлаждение образца до температуры $-50{ }^{\circ} \mathrm{C}$ проводили с шагом сканирования температуры, равным $5{ }^{\circ} \mathrm{C} /$ мин, до температуры на несколько десятков градусов ниже его температуры стеклования. Образец выдерживали при этой температуре в течение нескольких минут, а затем нагружали «застеклован- 
ный» полимер грузом 25 г и нагревали со скоростью, равной скорости снижения температуры при замораживании. Для построения термомеханической кривой (ТМК) в координатах деформация - температура использовали две функции: деформация - время и температура - время. Термомеханический анализ заканчивали при достижении температуры установившегося (стабильного) молекулярного течения продуктов термодеструкции древесины.

\section{Результаты и обсуждение}

Влияние времени воздействия ультразвука на молекулярно-топологическое строение древесинь дуба при соосной ориентации векторов. Количественные и молекулярно-релаксационные характеристики древесины дуба до и после воздействия ультразвука, рассчитанные и снятые непосредственно из ТМК, приведены в таблице 1 и рисунках 1-6.

Анализ данных ТМС (табл. 1) показал, что в древесине присутствуют два блока: аморфный блок псевдосетчатого строения и кластерный блок линейного строения, включающий узлы разветвления псевдосетки. Такая изотропность структуры древесины дуба определяется разнообразием макро- и микроскопических морфологических элементов древесины и различием надмолекулярного строения полимеров, входящих в структуру этих элементов. Данные, полученные методом ТМС, соответствуют суждениям о древесине как о полимерной композиции, представляющей собой полувзаимопроникающую сетку [2].

Воздействие на древесину ультразвука в течение 120 с приводит к существенному изменению всех молекулярно-релаксационных и количественных характеристик как в псевдосетчатой структуре аморфного блока, так и в кластерных блоках, включающих узлы разветвления (табл. 1). Увеличение времени ультразвуковой обработки древесины до двух минут изменяет молекулярную подвижность макромолекул в межузловых цепях в псевдосетчатой структуре аморфного блока, что отражается на температуре их стеклования $\left(\mathrm{T}_{\mathrm{c}}\right)$. Минимальное значение $\mathrm{T}_{\mathrm{c}}$ отмечено при $-8{ }^{\circ} \mathrm{C}$ и воздействии ультразвука в течение $20 \mathrm{c}$ (рис. 1 , кривая $\|$ ). Такое экстремальное изменение подвижности макромолекул в межузловых цепях связано, скорее всего, с локальным воздействием ультразвука на структуру как «узлов» между кластерами, так и самих кластеров. Иначе говоря, ультразвук механически разрывает связи не только между макромолекулами, входящими в состав «узлов», но и разрыхляет структуру макромолекул самих кластеров, действуя на их структуру. Это способствует созданию новых связей между макромолекулами кластеров и межкластерных блоков (узлов разветвления псевдо-сетки).

Эти предположения о воздействия ультразвука на древесину дуба могут объяснить экстремальный характер изменения не только температуры стеклования (рис. 1, кривая $\|$ ), молекулярные массы межузловых цепей псевдо-сетки аморфного блока (рис. 3, кривая $\|$ ) и цепей в кластере (рис. 4, кривая $\|$ ), но и усредненной по блокам ММ компонентов древесины (рис. 5, кривая $\|$ ). Свободный объем $\mathrm{V}_{\mathrm{f}}$, характеризующий подвижность цепей и плотность их упаковки в объеме древесины, в начале УЗ обработки падает, а с увеличением времени воздействия УЗ возрастает (рис. 6, кривая $\|$ ). Очевидно, что резкое увеличение ММ при одновременном уменьшении объема после ультразвуковой деструкции обусловлено возможностью появления новых физических (ионное взаимодействие, силы Ван-дер-Ваальса) связей с осколками межузловых цепей или собственной рекомбинации кластерных макрорадикалов, сближенных относительно друг друга. При увеличении времени воздействия УЗ пространственное разъединение (увеличение $\mathrm{V}_{\mathrm{f}}$ ) деформированных структур не способствует появлению физических взаимодействий. Данные прямо или косвенно свидетельствуют о механико-силовом воздействии ультразвука на древесину дуба.

Раздвижению фибриллярных рядов и разрыву водородных и межмолекулярных связей смежных волокон могут способствовать колебательные деформации клеточной стенки волокон и содержащихся в них высокомолекулярных соединений.

Данные ТМС подтверждают результаты воздействия УЗ на древесину дуба, полученные ранее с использованием анатомических и химических методов [9-14]. Как в воздушной, так и в водно-спиртовой среде анатомическая структура древесины дуба под действием акустических колебаний нарушается, изменяются морфологические параметры ее элементов. Такие структурные элементы древесины дуба, как волокна либриформа, крупные и мелкие сосуды, по-разному реагируют на действие ультразвука. Особенно большое влияние ультразвук оказывает на структурные элементы малых размеров, что, вероятно, связано с наличием в них адсорбированной воды, в присутствии которой могут возникнуть явления кавитации. Так, уже при коротких экспозициях под воздействием ультразвука высокой мощности увеличивается пло- 
щадь поперечного сечения мелких сосудов и пористость волокон либриформа [3, 5], механически рвутся клеточные стенки. Механическое разрушение клеточных стенок прямо указывает на разрушение полимеров в морфологических структурах.

Таблица 1. Характеристики молекулярно-топологического строения древесины дуба после ультразвукового воздействия при соосной ориентации векторов - оси зонда и роста дерева $(\|)$

\begin{tabular}{c|c|c|c|c|c}
\hline \multirow{2}{*}{$\begin{array}{c}\text { Характеристики } \\
\text { древесины }\end{array}$} & \multicolumn{5}{|c}{ Время ультразвуковой обработки, с } \\
\cline { 2 - 6 } & 0 & \multicolumn{5}{c}{20} & \multicolumn{2}{c}{60} & 120 \\
\hline \multicolumn{7}{|c|}{ Низкотемпературный аморфный блок псевдосетчатого строения } \\
\hline$\alpha_{1} \times 10^{5}{ }^{\circ} \mathrm{C}^{-1}$ & 1,00 & 1,60 & 2,80 & 2,71 & 2,53 \\
$\alpha_{2} \times 10^{5}{ }^{\circ} \mathrm{C}^{-1}$ & 3,76 & 5,50 & 8,53 & 9,73 & 10,5 \\
$\mathrm{~K}$ & 1,76 & 1,60 & 1,72 & 1,81 & 1,86 \\
$\varphi_{\mathrm{a}}$ & 0,85 & 0,78 & 0,74 & 0,76 & 0,88 \\
\hline \multicolumn{7}{|c|}{ Кластерный блок линейного строения и узлы разветвления псевдосетки } \\
\hline $\mathrm{T}_{\text {пл }}{ }^{\circ} \mathrm{C}$ & 228 & 232 & 241 & 241 & 247 \\
$\alpha_{3} \times 10^{5}{ }^{\circ} \mathrm{C}^{-1}$ & $-28,8$ & $-22,2$ & $-19,1$ & $-17,8$ & $-16,0$ \\
$\varphi_{\mathrm{\kappa}}$ & 0,15 & 0,22 & 0,26 & 0,24 & 0,12 \\
$\mathrm{~T}_{\mathrm{r}},{ }^{\circ} \mathrm{C}$ & 250 & 265 & 282 & 268 & 270 \\
\hline
\end{tabular}

Примечания: $\alpha_{1}$ - коэффициент линейного термического расширения в стеклообразном состоянии; $\alpha_{2}-$ коэффициент линейного термического расширения в области плато высокоэластичности аморфных блоков; К - коэффициент полидисперсности; $\varphi_{\mathrm{a}}$ - весовая доля аморфного блока; $\alpha_{3}$ - коэффициент плавления кристаллической фракции; $\varphi_{\mathrm{K}}-$ весовая доля кристаллического блока; $\mathrm{T}_{\text {пл }}$ - температура плавления кристаллического блока; $\mathrm{T}_{\mathrm{T}}-$ температура течения

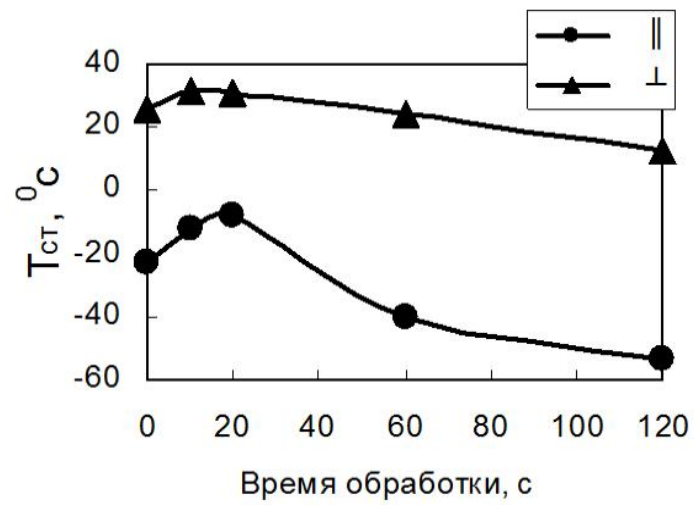

Рис. 1. Зависимость температуры стеклования ( $\left.\mathrm{T}_{\mathrm{c}}\right)$ древесины дуба от времени воздействия ультразвука

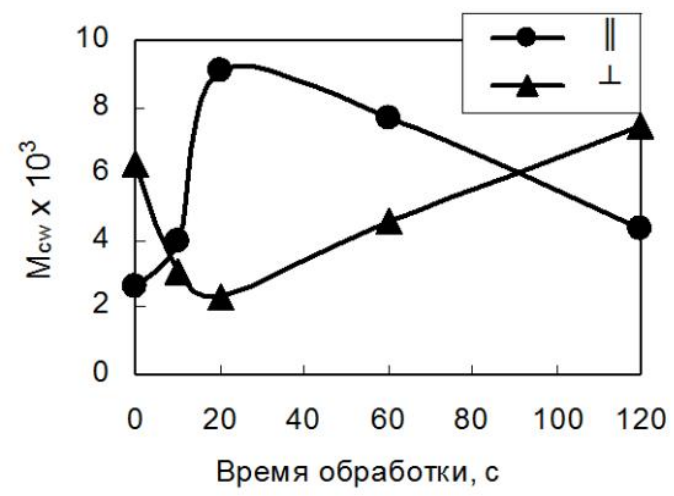

Рис. 3. Зависимость средневесовой молекулярной массы $\left(\mathrm{M}_{\mathrm{cw}}\right)$ межузловых цепей в псевдосетке аморфного блока древесины дуба от времени воздействия ультразвука

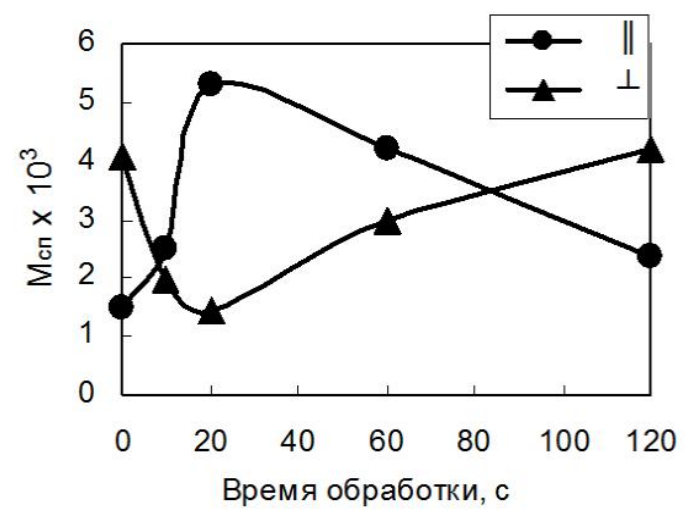

Рис. 2. Зависимость среднечисловой молекулярной массы $\left(\mathrm{M}_{\mathrm{cn}}\right)$ межузловых цепей в псевдосетке аморфного блока древесины дуба от времени воздействия ультразвука

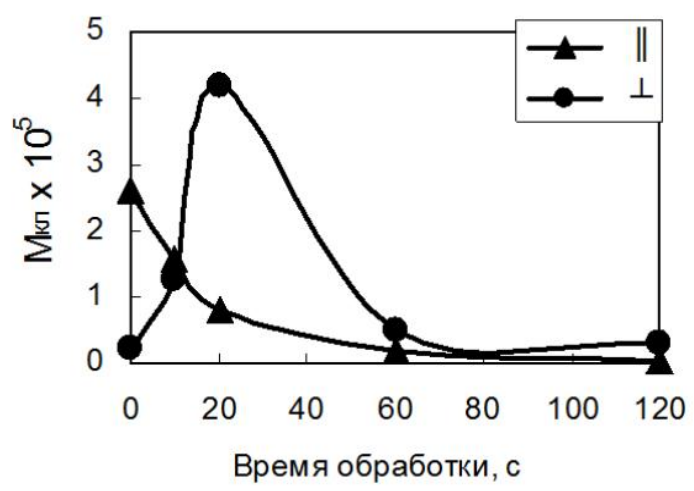

Рис. 4. Зависимость средневесовой молекулярной массы цепей кластерного блока $\left(\mathrm{M}_{\text {кл }}\right)$ древесины дуба от времени воздействия ультразвука 


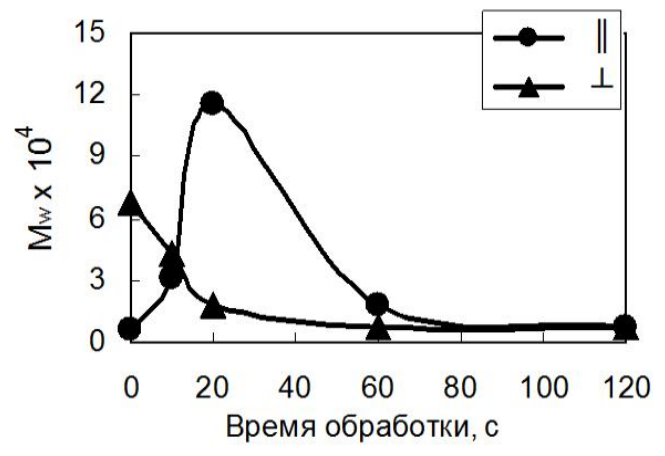

Рис. 5. Зависимость усредненной по блокам средневесовой молекулярной массы $\left(\mathrm{M}_{\mathrm{w}}\right)$ компонентов древесины от времени воздействия ультразвука

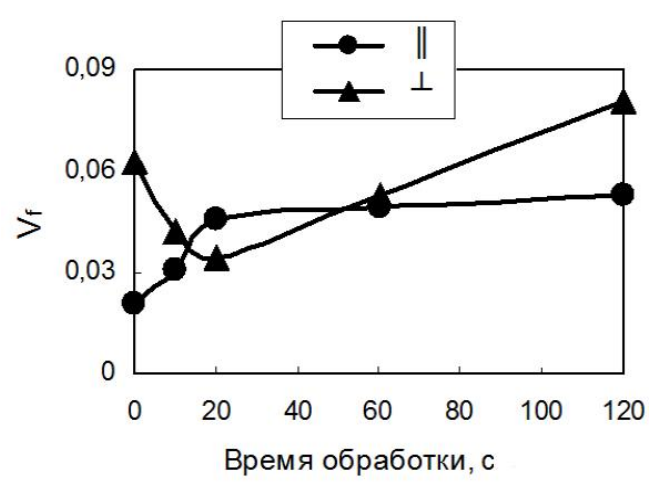

Рис. 6. Зависимость геометрического свободного объема $\left(\mathrm{V}_{\mathrm{f}}\right)$, характеризующего подвижность цепей и плотность их упаковки в объеме древесины дуба, от времени воздействия ультразвука

Разрушение химических и физических связей между компонентами приводит к изменению их структуры и свойств, снижается содержание высокомолекулярных веществ и увеличивается количество низкомолекулярных компонентов, благодаря чему изменяется их растворимость в воде и спиртовых растворах $[5,6]$. Гистохимические и спектральные (ИК-спектроскопия) методы исследования показали, что после воздействия на древесину УЗ значительные структурные изменения претерпевает лигнин древесины дуба [6], Воздействие ультразвука даже невысокой мощности вызывает в древесине дуба деполимеризацию лигнина, изменение его структуры и увеличение растворимости в спирте [13]. Нарушение структуры древесины и самого лигнина может происходить также из-за накопления в среде под влиянием кавитации гидроксил-радикалов и перекиси водорода $[14,15]$.

Влияние времени воздействия ультразвука на молекулярно-топологическое строение древесины дуба при взаимно перпендикулярной ориентации векторов. Данные ТМС при взаимно перпендикулярной ориентации векторов $(\perp)$ после ультразвукового воздействия в том же временном интервале, как и при анализе в ( $\|)$-варианте, тоже показали присутствие в древесине двух блоков, что свидетельствует о полностью аморфной структуре древесины, псевдосетчатое строение которой сформировано узлами разветвления кластерного и топологического типов. Молекулярно-релаксационные и количественные характеристики этих блоков приведены в таблице 2.

Сравнение молекулярно-релаксационных характеристик исходной древесины дуба, приведенных в таблицах 1 и 2 и рисунках 1-6, показывает существенные различия большинства анализируемых параметров, что свидетельствует о молекулярно-релаксационной анизотропии древесины относительно оси дерева и обусловлено различием пространственного расположения морфологических элементов, их размеров и надмолекулярного строения составляющих их полимеров.

Эти различия в изотропной структуре древесины относительно оси дерева находят отражение в реакции структурных блоков на действие ультразвука. Так, из таблиц и рисунка 1 следует, что молекулярные цепи полимер-гомологов, входящие в морфологические структуры, ориентированные вдоль оси роста дерева с отклонением от нее не более чем на 45 градусов, более подвижны, чем цепи перпендикулярной ориентации морфологических структур. В обоих случаях минимум подвижности отмечался после воздействия УЗ в течение 20 с, что свидетельствует о радикальном структурном изменении древесины.

Деструкцию кластеров и дальнейшее превращение их молекулярных фрагментов (осколков) в обоих анизотропных вариантах их нахождения в древесине иллюстрируют рисунки 4 и 5 (кривые $\|$ и $\perp$ ). Средневесовая ММ закристаллизованных цепей $\left(\mathrm{M}_{\text {кл }}\right)$ и усредненная по блокам средневесовая ММ компонентов межузловых цепей $\left(\mathrm{M}_{\mathrm{w}}\right)$ в структурах, ориентированных перпендикулярно оси дерева, последовательно снижаются с увеличением времени обработки, тогда как при параллельной ориентации наблюдается экстремум при $20 \mathrm{c}$. 
Таблица 2. Характеристики молекулярно-топологического строения древесины дуба после ультразвукового воздействия при взаимно-перпендикулярной ориентации векторов - оси зонда и роста дерева $(\perp)$

\begin{tabular}{c|c|c|c|c|c}
\hline \multirow{2}{*}{$\begin{array}{c}\text { Характеристики дре- } \\
\text { весины }\end{array}$} & \multicolumn{5}{|c}{ Время ультразвуковой обработки, с } \\
\cline { 2 - 6 } & 0 & 10 & 20 & 60 & 120 \\
\hline \multicolumn{7}{|c|}{ Низкотемпературный аморфный блок псевдосетчатого строения } \\
\hline$\alpha_{1} \times 10^{5}{ }^{\circ} \mathrm{C}^{-1}$ & 2,84 & 1,96 & 1,44 & 2,35 & 2,74 \\
$\alpha_{2} \times 10^{5}{ }^{\circ} \mathrm{C}^{-1}$ & 9,86 & 6,55 & 5,22 & 8,35 & 12,2 \\
$\mathrm{~K}$ & 1,55 & 1,56 & 1,60 & 1,55 & 1,76 \\
$\varphi_{\mathrm{a}}$ & 0,76 & 0,74 & 0,81 & 0,82 & 0,86 \\
\hline \multicolumn{7}{|c|}{ Кластерный блок линейного строения } \\
\hline $\mathrm{T}_{\text {пл, }}{ }^{\circ} \mathrm{C}$ & 195 & 197 & 201 & 198 & 210 \\
$\alpha_{3} \times 10^{5}{ }^{\circ} \mathrm{C}^{-1}$ & $-47,2$ & $-33,7$ & $-49,2$ & $-62,5$ & $-76,2$ \\
$\varphi_{\mathrm{\kappa}}$ & 0,24 & 0,26 & 0,19 & 0,18 & 0,14 \\
$\mathrm{~T}_{\mathrm{r}},{ }^{\circ} \mathrm{C}$ & 234 & 231 & 229 & 219 & 220 \\
\hline
\end{tabular}

Примечания: $\alpha_{1}-$ коэффициент линейного термического расширения в стеклообразном состоянии; $\alpha_{2}-$ коэффициент линейного термического расширения в области плато высокоэластичности аморфных блоков; К - коэффициент полидисперсности; $\varphi_{\mathrm{a}}$ - весовая доля аморфного блока; $\alpha_{3}-$ коэффициент плавления кристаллической фракции; $\varphi_{\mathrm{K}}-$ весовая доля кристаллического блока; $\mathrm{T}_{\text {пл }}-$ температура плавления кристаллического блока; $\mathrm{T}_{\mathrm{T}}-$ температура течения.

Расширение полимерных структур в блоках тоже происходит по-разному. Геометрический свободный объем $\left(\mathrm{V}_{\mathrm{f}}\right)$ аморфного блока при соосной ориентации векторов постоянно повышается с увеличением времени воздействия УЗ, тогда как при перпендикулярной ориентации - вначале падает, а затем резко увеличивается (рис. 6, кривая $(\perp)$.

Результаты показывают, что усредненная по блокам ММ полимер-гомологов в древесине в обеих ее анизотропных областях, как и характер ее изменения под действием ультразвука, лимитируется в основном молекулярной массой кластерной составляющей. Молекулярная структура этой составляющей, цепи которой являются последними участниками всех релаксационных процессов в древесине, определяют и время начала ее молекулярного течения ( $\left.\mathrm{T}_{\mathrm{T}}\right)$ (табл. 1 и 2).

Возможно также, что различный характер изменения молекулярной массы компонентов в кластерных осколках от времени воздействия ультразвука обусловлен разной ориентацией и долей участия кластера в морфологических структурах древесины. Отсюда, по-видимому, то различие, которое появляется в характере дальнейшего поведения кластера, - появление новых связей с осколками межузловых цепей после ультразвуковой деструкции или собственная рекомбинация кластерных макрорадикалов.

Можно предположить, что при распространении ультразвуковой волны на отдельных участках (изза превращения акустической энергии в тепловую) возникают напряжения, соизмеримые с энергией химической связи. В результате связь может разорваться, образуя макромолекулы, обладающие высокой реакционной способностью.

\section{Выводы}

1. Данные термомеханической спектроскопии показали, что структура древесины дуба представляет диблочную аморфно-кластерную композицию псевдосетчатого строения.

2. Под действием ультразвуковых волн топологическая изотропность псевдосетчатой структуры древесины претерпевает радикальные изменения как в аморфной, так и в кластерной составляющей.

3. Установлены различия молекулярно-релаксационных характеристик древесины в аксиальном и радиальном направлениях относительно оси роста дерева до и после воздействия ультразвука. Экстремальное время воздействия ультразвука (с частотой 21,5 кГц и интенсивностью излучения 15 Вт/см²) на древесину, при котором характеристики имеют либо минимальное, либо максимальное значение, составляет $20 \mathrm{c}$.

4. Предполагается, что характер структурных изменений обусловлен возникновением новых физических связей между фрагментами аморфных и кластерных блоков в обеих анизотропных структурах, разрушенных под влиянием ультразвука. Расшатывание структур при увеличении времени обработки УЗ такое взаимодействие снижает. 
5. Различие в характере изменения молекулярной массы компонентов кластерных осколков от времени воздействия ультразвука зависит, по-видимому, также от ориентации морфологических структур в исходной древесине, т.е. от расположения их в аксиальном или радиальном направлении относительно оси роста дерева.

\section{Сиисок литературы}

1. Вихров В.Е. Строение и физико-механические свойства ранней и поздней древесины дуба // Труды Института леса АН СССР. 1953. Т. ІХ. С. 29-38.

2. Эриньш П.П. Строение и свойства древесины как многокомпонентной системы // Химия древесины. 1977. №1. C. 8-25.

3. Коновалова Н.Н., Коновалов Н.Т., Стасова В.В., Антонова Г.Ф. Воздействие акустических колебаний на анатомическую структуру древесины дуба // Материалы Всероссийской конференции «Новые достижения в химии и химической технологии растительного сырья». Барнаул, 2002. С. 68-71.

4. Шмытько И.М., Коновалов Н.Т., Классен Н.В., Арнаутова Е.А., Коновалова Н.Н., Антонова Г.Ф. Структурные аспекты строения древесины дуба и его компонентов // Материаловедение. 2004. №10. С. 37-43.

5. Konovalova N.N., Konovalov N.T., Bazhenov A.N., Stasova V.V., Varaksina T.N., Antonova G.F. The effects of supersonic treatment on the structure and componenets of oak wood // Proceedings of $5^{\text {th }}$ IUFRO (Division 5) Symposium "Wood Structure and Properties '06". Zvolen, Slovakia, 2006. Pp. 59-65.

6. Антонова Г.Ф., Баженов А.В., Вараксина Т.Н., Коновалов Н.Т., Коновалова Н.Н., Стасова В.В. Влияние ультразвука на лигнин древесины дуба // Химия растительного сырья. 2006. №3. С. 5-16.

7. А.с. №427483 (СССР) / Ю.А. Ольхов, Я.И. Эстрин / 1988.

8. Патент № 1763952 (РФ). Способ измерения густоты пространственной сетки сшитых полимеров / Ю.А. Ольхов, Я.И. Эстрин / 1991.

9. Ольхов Ю.А., Черников С.С., Михайлов А.И. Безрастворный анализ молекулярно-массовых распределений в растительных полимерах лигнина, целлюлозы и древесины термомеханическим методом // Химия растительного сырья. 2001. №2. С. 83-96.

10. Базарнова Н.Г., Карпова Е.В., Катраков И.Б., Маркин В.И., Микушина И.В., Ольхов Ю.А., Худенко С.В. Методы исследования древесины и ее производных. Барнаул, 2002. С. 65-125.

11. Ольхов Ю.А., Базарнова Н.Г., Токарева И.В. Изучение молекулярно-топологической структуры древесины осины методом термомеханической спектрометрии // Известия вузов. Химия и химическая технология. 1998. Т. 41, вып. 6. С. 124-132.

12. Базарнова Н.Г., Катраков И.Б., Керницкий В.С., Ольхов Ю.А. Изучение превращений древесины осины в реакции бензилирования // Пластические массы. 1998. №8. С. 35-37.

13. Микушина И.В., Троицкая И.Б., Душкин А.В., Ольхов Ю.А., Базарнова Н.Г. Изменения в структуре древесины и ее компонентов в зависимости от твердофазного карбоксиметилирования // Химия растительного сырья. 2003. №2. C. 19-26.

14. Левинсон М.С. О реакциях химического воздействия ультразвука на воду и растворенные в ней вещества // О химическом и биологическом действии ультразвука. Красноярск, 1962. С. 5-74.

15. Янковский Б.А., Першина Л.А. О действии ультразвука на древесину // Химия древесины. 1969. Вып. 3. C. 57-62. 
Antonova G.F..$^{*}$, Olkhov Yu.A. ${ }^{2}$, Konovalov N.T. ${ }^{3}$ STRUCTURAL CHANGES IN OAK WOOD UNDER THE EFFECT OF ULTRASOUND

${ }^{1}$ Institute of Forest of V.N. Sukacheva SB RAS, Akademgorodok, Krasnoyarsk, 660036 (Russia),

e-mail: institute_forest@ksc.krasn.ru

${ }^{2}$ Institute of Problems of Chemical Physics RAS, pr. ac. Semenova, 1, Chernogolovka, 142432 (Russia)

${ }^{3}$ Institute of Solid State Physics, ul. ac. Osip'yan, 2, Chernogolovka, 142432 (Russia)

Structural changes in oak wood under the effect of ultrasound were studied by the method of thermomechanical spectroscopy. Molecular-relaxational characteristics of oak wood into axial and radial directions respectively to tree axis growth before and after the effect of ultrasound were examined. The reactions of structural block have been found to depend on spatial distribution of morphological elements of wood and theirs sizes with regard to the axis's of tree and under molecular structure of polymers.

Keywords: thermomechanical spectroscopy, oak wood, ultrasound.

\section{References}

1. Vihrov V.E. Trudy Instituta lesa AN SSSR, 1953, vol. IX, pp. 29-38. (in Russ.).

2. Jerin'sh P.P. Himija drevesiny, 1977, no. 1, pp. 8-25. (in Russ.).

3. Konovalova N.N., Konovalov N.T., Stasova V.V., Antonova G.F. Materialy Vserossijskoj konferencii «Novye dostizhenija v hi-mii i himicheskoj tehnologii rastitel'nogo syr'ja». [All-Russian Conference "New advances in chemistry and chemical engineering plant raw material"]. Barnaul, 2002, pp. 68-71. (in Russ.).

4. Shmyt'ko I.M., Konovalov N.T., Klassen N.V., Arnautova E.A., Konovalova N.N., Antonova G.F. Materialovedenie, 2004, no. 10, pp. 37-43. (in Russ.).

5. Konovalova N.N., Konovalov N.T., Bazhenov A.N., Stasova V.V., Varaksina T.N., Antonova G.F. Proceedings of $5^{\text {th }}$ IUFRO (Division 5) Symposium "Wood Structure and Properties '06". Zvolen, Slovakia, 2006, pp. 59-65.

6. Antonova G.F., Bazhenov A.V., Varaksina T.N., Konovalov N.T., Konovalova N.N., Stasova V.V. Himija rastitel'nogo syr'ja, 2006, no. 3, pp. 5-16. (in Russ.).

7. Patent 427483 (SU). 1988. (in Russ.).

8. Patent 1763952 (RU). 1991. (in Russ.).

9. Ol'hov Ju.A., Chernikov S.S., Mihajlov A.I. Himija rastitel'nogo syr'ja, 2001, no. 2, pp. 83-96. (in Russ.).

10. Bazarnova N.G., Karpova E.V., Katrakov I.B., Markin V.I., Mikushina I.V., Ol'hov Ju.A., Hudenko S.V. Metody issledovanija drevesiny i ee proizvodnyh. [Methods of study of wood and its derivatives]. Barnaul, 2002, pp. 65-125. (in Russ.).

11. Ol'hov Ju.A., Bazarnova N.G., Tokareva I.V. Izvestija vuzov. Himija i himicheskaja tehnologija, 1998, vol. 41, no. 6, pp. 124-132. (in Russ.).

12. Bazarnova N.G., Katrakov I.B., Kernickij V.S., Ol'hov Ju.A. Plasticheskie massy, 1998, no. 8, pp. 35-37. (in Russ.).

13. Mikushina I.V., Troickaja I.B., Dushkin A.V., Ol'hov Ju.A., Bazarnova N.G. Himija rastitel'nogo syr'ja, 2003, no. 2, pp. 19-26. (in Russ.).

14. Levinson M.S. O himicheskom i biologicheskom dejstvii ul'trazvuka. [On the chemical and biological action of ultrasound]. Krasnojarsk, 1962, pp. 5-74. (in Russ.).

15. Jankovskij B.A., Pershina L.A. Himija drevesiny, 1969, no. 3, pp. 57-62. (in Russ.).

Received March 18, 2014

\footnotetext{
* Corresponding author.
} 